\title{
Ketogenic Diet
}

\author{
Radhika Dhamija, Susan Eckert, Elaine Wirrell
}

\begin{abstract}
About one third of patients with epilepsy are pharmacoresistent. For a subgroup of this population, the ketogenic diet can be highly efficacious and should be considered early. This review discusses the different types of ketogenic diet, proposed mechanism of actions and its evidence for use in children and adults with both generalized and focal epilepsies where surgery is not feasible. In addition we discuss a practical approach to diet initiation, maintenance and monitoring for side effects. We also summarize the emerging evidence for the use of ketogenic diet in a broad range of neurological disorders.
\end{abstract}

RÉSUMÉ: Diète cétogène. Environ le tiers des patients atteints d'épilepsie sont pharmacorésistants. Pour un sousgroupe de ces patients, la diète cétogène peut être très efficace et devrait être considérée tôt au cours du traitement. Dans cette revue, nous discutons de différents types de diète cétogène, des mécanismes d'action proposés et des données appuyant son utilisation chez les enfants et les adultes présentant tant une épilepsie généralisée qu'une épilepsie focale, chez qui la chirurgie n'est pas une option. De plus, nous discutons d'une approche pratique à l'implantation de la diète, à son maintien et à la surveillance des effets secondaires. Nous présentons également un sommaire des observations récentes concernant l'utilisation d'une diète cétogène dans une panoplie de troubles neurologiques.

Can J Neurol Sci. 2013; 40: 158-167

In historic times before medications were popular, dietary alterations were prescribed for a variety of illnesses including epilepsy. Ancient Greek physicians treated epilepsy, by changing their patients' diet. An early treatise in the Hippocratic Corpus, "On the Sacred Disease", from 400 BC argued against the existing view that epilepsy was supernatural in origin, and proposed that dietary therapy had a rational basis ${ }^{1}$.

The first modern study of fasting as a treatment for epilepsy was in France in 1911. Twenty patients were treated with a lowcalorie vegetarian diet, combined with periods of fasting and purging. While two benefited greatly, most failed to maintain compliance $^{2}$. Around this time, Bernarr Macfadden, an American exponent of physical culture, popularized the use of fasting to restore health. His student, Hugh Conklin, an osteopathic physician from Michigan, began to treat his epilepsy patients with fasting. Later analysis of Conklin's case records showed $20 \%$ of his patients achieved seizure-freedom and $50 \%$ had some improvement. ${ }^{3}$ Conklin's fasting therapy was later adopted by many neurologists, including Dr. Geyelin at the Presbyterian Hospital in New York 4 .

While fasting may be an option in short term control of seizures, it is clearly not a long term treatment. In 1921, Dr. Wilder at Mayo Clinic first proposed the ketogenic diet (KD), which was designed to mimic fasting state but to provide adequate protein and calories for growth, and as such, to be a long term option for control of epilepsy ${ }^{5}$. The ketogenic diet became more widely used at that time as there were only a few anticonvulsant medications available including bromides (1857) and phenobarbital (1912). However as more anticonvulsants came on the market, the ketogenic diet was used only in limited settings. In an attempt to make the diet more palatable, the medium chain triglyceride (MCT) KD was introduced and used in various childhood epilepsy syndromes ${ }^{6,7}$. However in the last two decades, advocacy groups, such as the Charlie Foundation and Matthew's Friends have facilitated a reemergence of interest and research in this diet which is now used throughout the world to treat patients with intractable epilepsy ${ }^{8}$. A large single center study on a cohort of children with intractable epilepsy showed marked improvement in $>60 \%$ of the patients ${ }^{9}$. Similar results ( $>50 \%$ patients with $>50 \%$ reduction in seizures at six months) were found in a large multicentre study on children between age one to eight years with more than ten seizures per week at baseline ${ }^{10}$. The first randomized, prospective, controlled trial utilizing the KD in children was published in 2008 and examined 145 children (2 -16 years) who had at least daily seizures and had failed to respond to at least two antiepileptic drugs. After three months, seizures was significantly lower in the diet group than in controls $(75 \% \text { decrease, } \mathrm{p}<0.0001)^{11}$.

Table 1 summarizes important studies done using the various forms of the KD and their efficacy in decreasing seizure frequency.

From the Division of Child and Adolescent Neurology, Mayo Clinic Children's Center, Rochester, MN, USA.

Received June 25, 2012. Final Revisions Submitted September 6, 2012. Correspondence to: Elaine Wirrell, Division of Child and Adolescent Neurology, Mayo Building, 16th floor, Mayo Clinic, 200 First Street SW, Rochester, MN, 55905, USA. Email: wirrell.elaine@mayo.edu. 
Table 1: Efficacy of different types of ketogenic diets in patients with intractable epilepsy

\begin{tabular}{|c|c|c|}
\hline \multirow{2}{*}{$\begin{array}{l}\text { Traditional ketogenic diet } \\
\text { Study }\end{array}$} & \multirow[b]{2}{*}{ Number of patients } & \multirow[b]{2}{*}{$\underline{\text { Response Rate }}$} \\
\hline & & \\
\hline Kinsman et al 1992 & 58 children ( $>=2$ AED's and multiple seizure types) & $67 \%$ had $>50 \%$ reduction at 6 months \\
\hline Vining et al 1998 & 51 children (>10 seizures/week) & $50 \%$ had $>50 \%$ reduction at 6 months \\
\hline DiMario et al 2001 & 24 children (multiple seizure types) & $54 \%$ had $>50 \%$ reduction at 6 months \\
\hline Kang 2005 & 199 children ( $>=4$ seizures/month and $>=3$ AED's) & $58 \%$ had $>50 \%$ reduction at 6 months \\
\hline Neal et al 2009 & 73 children (daily seizures and $>=2$ AED's) & $25 \%$ had $>50 \%$ reduction at 6 months \\
\hline Dressler 2010 & 50 children ( $>=2$ AED's) $)$ & $50 \%$ had $>50 \%$ reduction at 6 months \\
\hline Thamongkol 2012 & 64 children and 4 adults (failed $>=2$ AED's) & $48 \%$ had $>50 \%$ reduction at 3 months \\
\hline \multicolumn{3}{|l|}{$\begin{array}{l}\text { Medium chain } \\
\text { triglyceride oil diet }\end{array}$} \\
\hline Huttenlocher 1971 & 12 children $(>=2$ AED's) & $>50 \%$ had $>50 \%$ reduction at 6 months \\
\hline Mak et al 1999 & 13 children ( $>=2$ AED's and multiple seizure types) & $>70 \%$ had $>50 \%$ reduction at 6 months \\
\hline Neal et al 2009 & 72 (daily seizures and $>=2$ AED's) & $20 \%$ had $>50 \%$ reduction at 6 months \\
\hline \multicolumn{3}{|l|}{ Low glycemic index diet } \\
\hline Pfeifer et al 2005 & 20 patients ( $>=3$ AED's) & $50 \%$ had $>90 \%$ reduction at 6 months \\
\hline Muzykewicz 2009 & 76 children $(>=3$ AED's) & $54 \%$ had $>50 \%$ reduction at 6 months \\
\hline Coppolla 2011 & 15 patients ( 4 seizures/months and ( $>=3$ AED's) & $40 \%$ had a $75-90 \%$ reduction at 12 months \\
\hline \multicolumn{3}{|l|}{ Modified atkins diet } \\
\hline Kossoff et al 2006 & 20 children $(>3$ seizures/week and failed $>=2$ AED's) & $\begin{array}{l}65 \% \text { had }>50 \% \text { reduction at } 6 \text { months; } \\
35 \% \text { had }>90 \% \text { reduction }\end{array}$ \\
\hline Kossoff et al 2008 & 30 adults ( $>1$ seizures/week and failed $>=2$ AED's) & $33 \%$ had $>50 \%$ reduction at 6 months \\
\hline Weber et al 2009 & 20 children $(>1$ seizures/week and failed $>=2$ AED's) & $40 \%$ had $>50 \%$ reduction at 3 months \\
\hline Chen et al 2012 & 87 children $(>=2$ AED's) & $\begin{array}{l}55 \% \text { had }>50 \% \text { reduction at } 6 \text { months; } 38 \% \\
\text { had }>50 \% \text { seizure reduction at } 12 \text { months }\end{array}$ \\
\hline Kim et al 2012 & 20 children $(>=2$ AED's) & $45 \%$ had $>50 \%$ reduction \\
\hline
\end{tabular}

*AED's: Antiepileptic drugs

In a study surveying the use of this diet world wide, it was found that the overall physician and patient acceptance of the diet is high and cultural and religious issues are not limiting.

International collaborative groups are forming rapidly to study this diet ${ }^{12}$. A multicenter expert guideline that outlines the ideal manner in which to provide the ketogenic diet has also been published $^{13}$.

\section{Different types of ketogenic diet}

There are four different ketogenic diets available: the traditional 'classic' ketogenic diet (KD), the medium-chain triglyceride (MCT) ketogenic diet, the modified Atkins diet (MAD) and the low glycemic index treatment (LGIT). The composition of the diets and their pros and cons are discussed in Table 2.

The traditional "classic" ketogenic diet contains a fixed ratio by weight of fat to combined protein and carbohydrate. This is achieved by excluding high-carbohydrate foods while increasing the consumption of foods high in fat. In young children and infants, the traditional diet is frequently started in a hospital setting.

Most dietary fat is made of molecules called long-chain triglycerides. However, medium-chain triglycerides (MCTs) of octanoic and decanoic acids produce more ketones per unit of energy $^{7,14}$. A variant of the classic diet known as the MCT ketogenic diet uses MCT oil to provide around half the calories. As less overall fat is needed in this diet, a greater proportion of carbohydrate and protein can be consumed, allowing a slightly greater variety of food choices. This diet was first tested in 1971 by Dr. Huttenlocher on twelve children and adolescents with intractable seizures. A therapeutically significant anticonvulsant effect was seen in $50 \%$ of the children with a mean age of eight years with slightly higher incidence of gastrointestinal side effects $^{7}$. In another study on children with refractory epilepsy $>$ $50 \%$ of patients had $>75 \%$ reduction in seizure frequency using MCT diet ${ }^{15}$.

Modified Atkins diet allows for carbohydrate intake of 10$20 \mathrm{~g} /$ day and strongly encourages fat intake. There is no calorie restriction or meticulous weighing of food involved and hence meals are easier to prepare. It can be started in home setting. This diet appears to be well-tolerated and efficacious in most children $^{16}$. Long-term experience with this diet has also been reported in 87 children with intractable epilepsy, of which 54 continued for more than six months. After a mean of 19.9 months, 30 of $54(55 \%)$ children with diet durations of more than six months achieved $>50 \%$ improvement; 19 (35\%) were 
Table 2: Composition and pros/cons of the different ketogenic diets

\begin{tabular}{|c|c|c|c|}
\hline Diet & Composition & Pros & Cons \\
\hline $\begin{array}{l}\text { Classical } \\
\text { KD }\end{array}$ & $\begin{array}{l}\text { Can be any ratio but } \\
\text { typically } 3-4: 1 \\
\text { Based on } 4: 1 \text { ratio: } \\
90 \% \text { fat, } 4 \% \\
\text { carbohydrate, } 6 \% \text { protein }\end{array}$ & $\begin{array}{l}\text { Parents know exactly how much of each } \\
\text { food to give; } \\
\text { Very consistent, therefore little variation in } \\
\text { ketones; } \\
\text { Easy to adjust as dietician knows exactly } \\
\text { what child is getting; } \\
\text { Requires less record keeping by parents }\end{array}$ & $\begin{array}{l}\text { Difficult to adjust amount consumed based on child's appetite; } \\
\text { Child must eat everything on their plate; } \\
\text { Protein limited to recommended dietary allowance, } \\
\text { which is often less than child is used to; } \\
\text { Involves weighing and measuring; } \\
\text { more time-consuming to prepare the meals }\end{array}$ \\
\hline $\begin{array}{l}\text { Medium } \\
\text { Chain } \\
\text { Triglyceride }\end{array}$ & $\begin{array}{l}\text { Can be any ratio } \\
\text { Based on } 4: 1 \text { ratio: } \\
10 \% \text { LCT fat, } 60 \% \mathrm{MCT} \\
\text { fat, } 20 \% \text { carbohydrate, } \\
10 \% \text { protein }\end{array}$ & $\begin{array}{l}\text { Provides more protein; } \\
\text { Greater protein serving size allows more } \\
\text { volume in which to mix the fats and } \\
\text { increased variety of food; }\end{array}$ & $\begin{array}{l}\text { Involves weighing and measuring food; } \\
\text { time-consuming to prepare the meals; } \\
\text { Gastrointestinal side effects }\end{array}$ \\
\hline $\begin{array}{l}\text { Modified } \\
\text { Atkins }\end{array}$ & $\begin{array}{l}\text { Approx } 1.1: 1 \text { ratio } \\
65 \% \text { fat, } 10 \% \\
\text { carbohydrate, } 25 \% \\
\text { protein }\end{array}$ & $\begin{array}{l}\text { Greater flexibility to adjust meal to } \\
\text { variations in appetite; } \\
\text { Provides more protein; } \\
\text { Greater protein serving size allows more } \\
\text { volume in which to mix the fats; } \\
\text { Less weighing, measuring, faster meal prep; }\end{array}$ & $\begin{array}{l}\text { No firm guidelines regarding fat amounts; } \\
\text { Requires experimentation to determine adequate fats to ensure } \\
\text { desired ketosis; } \\
\text { Often more variability in ketone production; } \\
\text { Requires more record keeping to allow adjustments in diet }\end{array}$ \\
\hline $\begin{array}{l}\text { Low } \\
\text { glycemic } \\
\text { index diet }\end{array}$ & $\begin{array}{l}\text { Approx } 0.6: 1 \text { ratio } \\
60 \% \text { fat, } 10 \% \\
\text { carbohydrate, } 30 \% \\
\text { protein }\end{array}$ & $\begin{array}{l}\text { Greater flexibility to adjust meal to } \\
\text { variations in appetite; } \\
\text { Provides more protein; } \\
\text { Greater protein serving size allows more } \\
\text { volume in which to mix the fats; } \\
\text { Less weighing, measuring, faster meal prep; }\end{array}$ & $\begin{array}{l}\text { Requires knowledge of the foods that have low glycemic index; } \\
\text { Requires more record keeping to allow adjustments in diet }\end{array}$ \\
\hline
\end{tabular}

seizure-free. At 12 months, 33 of 87 (38\%) had $>50 \%$ seizure reduction; $16(18 \%)$ were seizure-free ${ }^{17}$.

The low glycemic index treatment is a low-carbohydrate diet (carbohydrate intake is usually limited to $40-60 \mathrm{~g} / \mathrm{day}$ ). Only foods with low glycemic index $(<50)$ are used. In a study on 20 patients who had failed at least three anticonvulsant medications previously, $50 \%$ had greater than $90 \%$ reduction in the seizures ${ }^{18}$. In another retrospective chart review study, $40 \%$ of the enrolled patients with generalized or focal seizures, refractory to at least three consecutive anticonvulsant drugs, with at least four seizures per month, had a $75-90 \%$ seizure reduction ${ }^{19}$.

In the author's experience, occasional children may show a robust reduction in seizures with a traditional ketogenic diet after responding suboptimally to a low glycemic or modified Atkins diet. But overall, the different types of ketogenic diets appear to have similar efficacy.

\section{Does ketosis matter?}

There is evidence in the literature that continued large ketosis (> $160 \mathrm{mg} / \mathrm{dl}$ ) is not always needed for seizure control, though higher ketosis can lead to improved seizure control in some patients. In a prospective study, 20 children, aged 3-18 years were treated for six months with modified Atkins diet. Carbohydrates were initially limited to $10 \mathrm{~g}$ per day and fats were encouraged. At six months, $80 \%$ remained on the diet, $65 \%$ experienced a $>50 \%$ reduction, and $35 \%$ a greater than $90 \%$ reduction in seizures. All children on the modified Atkins diet achieved moderate ketosis (> 80-160 mg/dl) within four days (mean 1.9 days) of diet initiation. Only 29\% maintained large ketosis long term. Large ketosis was not predictive of better outcome beyond one month. At six months, three of the five patients with zero to trace ketosis were $>90 \%$ improved, and a fourth patient was $50-90 \%$ improved $^{16}$.

While using the traditional $\mathrm{KD}$, the typical ratio used to obtain moderate to high urinary ketones is usually $3-4: 1$, with few children requiring a lower ratio. Ratio is based on the degree of ketosis and seizure control and is different for every child. In a study by Seo et al, the antiepileptic efficacy and diet tolerability of a $3: 1$ and 4:1 ratio were compared. Initial antiepileptic efficacy was higher for the 4:1 than the 3:1 diet (p $<0.05$ ), however dietary tolerability was better for the $3: 1$ than the 4:1 diet. For seizure-free patients who started on the 4:1 diet, antiepileptic efficacy was maintained after changing to the $3: 1$ $\operatorname{diet}^{20}$. Thus it appears reasonable to decrease the ratio in those with significant gastrointestinal intolerance without fear of losing efficacy.

It is often not possible to achieve moderate ketosis in the low glycemic index diet but this diet has been shown to have similar efficacy as discussed above ${ }^{19}$. Thus the degree of ketosis may be less important than previously thought.

\section{Indications and Evidence}

The ketogenic diet is most often considered in cases of refractory epilepsy and epileptic encephalopathies where surgery is not feasible. All types of seizures have been reported to respond to the ketogenic diet, although in the authors experience, while patients with focal epilepsy may improve, they do not achieve complete seizure freedom on $\mathrm{KD}^{13}$. The efficacy of the diet is not specific to any syndrome, although it is most commonly used in the epileptic encephalopathies of childhood. 
Evidence for the use of this diet exists both in adults and children, though predominantly in uncontrolled cohort studies.

The first randomized, prospective, controlled trial utilizing the KD in children was published in 2008 and examined 145 children (2 -16 years) who had at least daily seizures and had failed to respond to at least two antiepileptic drugs. Children were randomized to either receive KD or no change in treatment. After three months, seizures was significantly lower in the diet group than in controls $(75 \%$ decrease, $\mathrm{p}<0.0001)$. Twenty eight children $(38 \%)$ in the diet group had greater than $50 \%$ seizure reduction compared with only four $(6 \%)$ controls $(p<0.0001)$, and five children $(7 \%)$ in the diet group had greater than $90 \%$ seizure reduction compared with no controls $(\mathrm{p}=0.0582)$. There was no significant difference in the efficacy of the treatment between symptomatic generalized or symptomatic focal syndromes ${ }^{11}$.

\section{Evidence in Specific syndromes (Table 3)}

\section{Infantile Spasms}

A study from a single institution evaluating the efficacy of ketogenic diet in infantile spasms showed that there was $50 \%$ spasm improvement in nearly two thirds of children at six months and $77 \%$ after one to two years. Thirty seven percent became spasm-free for at least a six month period within a median 2.4 months of starting the KD. In addition, $62 \%$ reported improvement in neurodevelopment, 35\% had electroencephalogram (EEG) improvement, and 29\% were able to reduce concurrent anticonvulsants. Thus it is recommended that KD should be considered strongly after failure of corticosteroids, adrenocorticotrophic hormone (ACTH) and vigabatrin as a treatment for infantile spasms ${ }^{21}$. Another group compared short term use (eight months) vs long term traditional use (two years) of KD in infantile spasms. It was found that the use of the diet for only eight months in children who become spasm-free appears to be justified, with similar outcomes, recurrence rate, and less growth disturbance than a longer-term, traditional use $\mathrm{e}^{22}$. In the authors opinion, the KD is not an ideal first line therapy for infantile spasms as it usually takes longer to be effective compared to other first line therapies. Given the concern for adverse developmental impact of ongoing hypsarrhythmia, if used first line, the diet should be trialed for a maximum period of two weeks, and therapy switched at that time if there are ongoing spasms or persisting hypsarrhythmia.

\section{Dravet syndrome}

Ketogenic diet has been shown to be effective in children with Dravet syndrome. In two modest sized cohorts of children with Dravet syndrome placed on KD, nearly two thirds had a $>75 \%$ decrease in seizures. In addition to efficacy on seizure frequency, KD was beneficial on behavior disturbances including hyperactivity ${ }^{23-25}$. Thus, the diet should be considered early in the course of this syndrome.

\section{Myoclonic-atonic epilepsy}

Myoclonic-atonic epilepsy is an idiopathic generalized epilepsy syndrome affecting preschool-aged children. In a small study of 11 children with myoclonic-atonic epilepsy on a KD, Carabello found that over half showed a $>50 \%$ reduction in seizures, and seizure-freedom was seen in $18 \%{ }^{26}$. In ten patients treated with KD after an average of five antiepileptic medication trials, five achieved seizure freedom ${ }^{27}$. In a large retrospective study evaluating treatment and long term prognosis of 81

Table 3: Evidence in specific electroclinical syndromes

\begin{tabular}{|c|c|c|}
\hline Syndrome & Study & $\underline{\text { Response Rate }}$ \\
\hline Infantile Spasms & Hong et al 2010 & $\begin{array}{l}104 \text { infants ( } 64 \% \text { of children had } 50 \% \text { spasm } \\
\text { improvement at } 6 \text { months })\end{array}$ \\
\hline Dravet syndrome & $\begin{array}{l}\text { Caraballo et al } 2011 \\
\text { Nabbout, } 2011\end{array}$ & $\begin{array}{l}24 \text { children }(62.5 \% \text { had a } 75-99 \% \text { decrease in } \\
\text { seizures at } 2 \text { years after diet initiation }) \\
15 \text { children }(66 \% \text { had a decrease of seizure } \\
\text { frequency }>/=75 \% \text { at } 1 \text { month })\end{array}$ \\
\hline Myoclonic-astatic epilepsy & $\begin{array}{l}\text { Caraballo et al } 2006 \\
\text { Kilaru et al } 2007\end{array}$ & $\begin{array}{l}11 \text { children ( }>50 \% \text { had a }>50 \% \text { reduction in } \\
\text { seizures at } 18 \text { months.) } \\
10 \text { children ( } 50 \% \text { had seizure freedom at } 6 \text { months) }\end{array}$ \\
\hline Lennox-Gastaut syndrome & Lemmon et al 2012 & $\begin{array}{l}71 \text { children }(51 \% \text { had }>50 \% \text { seizure } \\
\text { reduction at } 6 \text { months })\end{array}$ \\
\hline $\begin{array}{l}\text { Febrile infection-related } \\
\text { epilepsy syndrome (FIRES) }\end{array}$ & Nabbout et al 2010 & $\begin{array}{l}9 \text { children ( }>70 \% \text { had }>50 \% \text { seizure } \\
\text { reduction at } 5 \text { days) }\end{array}$ \\
\hline $\begin{array}{ll}\text { Metabolic disorders: } \\
\text { - } & \text { Respiratory complex } \\
& \text { defect, Pyruvate } \\
& \text { dehydrogenase } \\
& \text { deficiency } \\
\text { - } & \text { Glucose transporter- } \\
& 1 \text { deficiency } \\
\text { - } & \text { Non ketotic } \\
& \text { hyperglycinemia }\end{array}$ & $\begin{array}{l}\text { Kang et al } 2007 \\
\text { Caraballo et al } 2011 \\
\text { Cusmai et al } 2012\end{array}$ & $\begin{array}{l}\text { KD considered first line based on mechanism } \\
3 \text { children (significant reduction of seizures) }\end{array}$ \\
\hline
\end{tabular}


children with myoclonic-atonic epilepsy, Oguni reported that the most effective treatment for myoclonic-atonic epilepsy was the ketogenic diet ${ }^{28}$. In conclusion, the diet should be considered early in the course of myoclonic-atonic epilepsy and not as a last resort.

\section{Lennox-Gastaut syndrome}

Similarly favorable outcomes have been seen in children with Lennox-Gastaut syndrome ${ }^{29,30}$. In a retrospective study from a single institution, of 71 children (range 18 months-18years), with Lennox-Gastaut syndrome who were initiated on the ketogenic diet, $51 \%$ achieved more than $50 \%$ seizure reduction, $23 \%$ more than $90 \%$ seizure reduction, and $1 \%$ achieved seizure freedom after six months ${ }^{31}$. In another retrospective, collaborative, multicenter study from Argentina involving 216 patients with various seizure syndromes started on the KD, $56.5 \%$ of the patients had a $>75 \%$ reduction in seizure frequency. The best results were found in patients with epilepsy with myoclonic atonic epilepsy, Lennox-Gastaut syndrome, and West syndrome ${ }^{23}$.

\section{Febrile infection-related epilepsy syndrome (FIRES)}

FIRES is a poorly understood and devastating condition triggered by fever of unknown cause. Status epilepticus may last more than one month, and this condition frequently evolves into pharmacoresistent epilepsy associated with severe cognitive impairment. Nabbout reported on nine patients over a 12 year period with FIRES who were treated with KD. In seven, KD was efficacious within a mean of 4.8 days following the onset of the diet. In one responder, early disruption of the diet was followed by relapse of intractable $\mathrm{SE}$. In conclusion, KD may be an alternative therapy for refractory SE in FIRES and should be considered early in pharmacoresistent cases $^{32}$.

\section{Focal etiologies}

There are reports of ketogenic diet being of benefit in refractory epilepsy due to focal lesions like hypothalamic hamartoma, cortical dysplasia and tuberous sclerosis ${ }^{27,33-35}$. In a retrospective chart review over five years, twelve children with tuberous sclerosis were identified from a single institution. All children had daily seizures at the time of diet initiation. Eleven children $(92 \%)$ had $>50 \%$ reduction in their seizures at six months on the KD and eight $(67 \%)$ had a $>90 \%$ response. Five children achieved seizure freedom for five months. The children remained on the KD for a mean of two years. Eight (67\%) children were able to reduce their antiepileptics while on the KD. There were no reported complications ${ }^{35}$.

\section{Status epilepticus (SE)}

Ketogenic diet has been successfully used in the treatment of refractory status epilepticus (convulsive and non convulsive) both in adults and children. It has been shown to decrease ventilation time and number of antiepileptic drugs. It has been suggested, based on limited data, that KD can be tried after failure to control ongoing seizures with standard measures for $\mathrm{SE}^{36}$.

\section{Mitochondrial disease}

A retrospective analysis evaluated outcomes in 14 children with intractable epilepsy and respiratory chain complex defects who were treated with the classic KD. The epileptic diagnoses were as follows: five patients with infantile spasms, four with the Lennox-Gastaut syndrome, one with the Landau-Kleffner syndrome, one with nonspecific generalized epilepsy, and three with focal epilepsy. Seven patients became seizure-free after commencing the $\mathrm{KD}$, one had $>90 \%$ seizure reduction, and two had seizure reductions between $50 \%$ and $90 \%$. Thus KD was a safe and effective therapy for seizures in children with intractable epilepsy and respiratory chain complex defects. ${ }^{37}$ However, the KD is contraindicated in carnitine deficiency, pyruvate carboxylase deficiency, and defects in fatty acid oxidation $^{13}$.

\section{Other metabolic disorders}

Ketogenic diet is considered first line in certain metabolic disorders like glucose transporter-1 (GLUT-1) deficiency and pyruvate dehydrogenase deficiency ${ }^{34}$. For the treatment of GLUT-1 deficiency syndrome, the modified Atkins diet has been shown to have similar effectiveness ${ }^{38}$. Cases of successful treatment of early myoclonic encephalopathy due to non ketotic hyperglycinemia using KD have also been described ${ }^{39}$.

Thus, based on the above evidence, we can conclude that most types of seizures respond to the ketogenic diet and the efficacy of the diet is not specific to any syndrome ${ }^{40}$.

\section{Evidence in adults}

Evidence for KD use is less robust in adults ${ }^{41}$ and its use in adults less frequent among practicing physicians. Only $38 \%$ of the consensus group offered dietary therapy to adults ${ }^{13}$. New diet options that are more palatable and flexible than the traditional $\mathrm{KD}$, such as the modified Atkins diet or low glycemic index diet have made this an attractive option for adults with intractable epilepsy. In a prospective open-label pilot study on KD treatment in adults with refractory epilepsy (generalized and focal), $50 \%$ of subjects had a $>50 \%$ reduction in seizures and $33 \%$ had a $>85 \%$ seizure reduction. The diet was felt to be well tolerated and adverse effects were mild: nausea, vomiting, diarrhea, constipation, and weight $\operatorname{loss}^{42}$. A prospective, open-label study performed on 30 adults ( $>18$ years-of-age, with at least weekly seizures, prior use of at least two anticonvulsants) using a modified Atkins diet showed that $47 \%$ had a $>50 \%$ seizure reduction after one and three months on the diet; $33 \%$ after six months ${ }^{43}$. The medium chain triglyceride ketogenic diet and low glycemic index treatments have not been studied systematically in adults.

In conclusion, data in adult population must be interpreted with caution as it is limited by small number of subjects. However, in the authors opinion, it is a reasonable option in medically intractable epilepsy in adults. In clinical practice compliance with the traditional KD seems to be a significant barrier in adults. The modified Atkins or low glycemic index diets are probably the best options for adults as they have better compliance, are better tolerated due to fewer gastrointestinal side effects and probable lower risk of dyslipidemia. 
To summarize, all the studies are heterogenous and difficult to compare but overall, regardless of age, seizure type, or etiology, the KD appears to provide a third of the patients with $>90 \%$ reduction in their seizure frequency and half of the patients greater than $50 \%$ reduction in seizure frequency ${ }^{44}$. In comparison vagal nerve stimulation has been studied in a randomized controlled fashion in children with intractable epilepsy and has been found to reduce seizure frequency by $>$ $50 \%$ in $>25 \%$ of the patients ${ }^{45}$. Addition of a third anticonvulsant has been found to be of benefit in $<5 \%$ of the patients ${ }^{46}$. Thus $\mathrm{KD}$ can be highly efficacious and should be considered early.

\section{Mechanism of action}

The exact mechanism of action of the diet is still unknown though there are a number of theories and ongoing research. Likely the KD works through multiple mechanisms. It is unlikely that these numerous hypotheses can be unified into a final common pathway; nevertheless, it is important to consider each of these putative mechanisms and discuss the evidence.

- Importance of ketones: The ketones may have direct antiepileptic activity or may act to stabilize neuronal membranes. The earliest demonstration of direct in vivo effects of ketone bodies was made in the early 1930s when it was determined that acetoacetate, when administered intraperitoneally in rabbits, prevented seizures induced by thujone, a convulsant and an antagonist of $\mathrm{GABA}_{\mathrm{A}}$ receptors ${ }^{47}$. Mice models for Dravet syndrome and genetic epilepsy with febrile seizures plus have been studied using the KD. Higher levels of $\beta$-hydroxybutyrate have been found in the mice with better seizure control compared to the mice treated with standard diet suggesting that ketones might have antiepileptic effects ${ }^{48}$. It has been shown in rat models that higher ratios of ketogenic diet $(6: 1)$, are more efficacious than traditional 4:1 ratio without more neurotoxic effects ${ }^{49}$. However, as discussed previously, human data suggests that the MAD and LGIT have efficacy similar to traditional KD even with a lower degree of ketosis; suggesting high ketosis may not be major mechanism in humans ${ }^{17-19,42}$.

- Role of polyunsaturated acids (PUFAs): It is hypothesized that specific polyunsaturated fatty acids regulate neuronal membrane excitability by blocking voltage gated sodium or calcium channels ${ }^{50}$. In a study comparing the blood levels of arachidonate (PUFA) before and three to four weeks after starting the KD in children, higher levels of arachidonate correlated with improved seizure control. Thus, elevated PUFA may represent a potential anticonvulsant mechanism of the $\mathrm{KD}^{51}$. However there are other clinical trials on humans which have not supported this concept and the results show discrepancies ${ }^{52}$. In a prospective randomized study on adults with uncontrolled epilepsy who were randomized to either mineral oil (placebo) $n=9$ or EPA (eicosapentaenoic acid) and DHA (docosahexaenoic acid) (ratio of 3:2) n=12; none on the n3 PUFA versus two on the placebo diet had at least a $50 \%$ decrease in seizure frequency from baseline ${ }^{53}$. Another 12 -week, double-blind crossover trial, showed no significant benefits of daily supplementation of EPA and DHA vs. placebo in patients with intractable epilepsy ${ }^{54}$.

- Anti-inflammatory and protection against excitotoxicity: Several theories have suggested that the KD has antiinflammatory effects and protects against excitotoxicity- mediated neuronal cell death ${ }^{55}$. It has been shown in hippocampal cell lines to interfere with glutamate-mediated toxicity, a major mechanism underlying neuronal injury ${ }^{56}$.

- Alteration in neuro-metabolites and/or their receptors: The $\mathrm{KD}$ can potentially alter the levels of neuro-metabolites and influence seizure control ${ }^{57}$. In-vivo studies have shown that $\beta$ hydroxybutyrate increases the brain synthesis of kynurenic acid, an endogenous antagonist of glutamatergic and $\alpha 7$-nicotinic receptors, thus potentially acting as an anticonvulsant ${ }^{58}$. In one study, the addition of either acetoacetate or $\beta$-hydroxybutyrate was associated with diminished consumption of glutamate via transamination to aspartate and increased formation of labeled $\mathrm{GABA}^{59}$. Recent positron emission tomography studies using flumazenil have suggested that KD may control seizures by directly or indirectly increasing the binding potential of the benzodiazepine receptors 60 .

- Positive energy balance: A study on rat brain reported that the KD increased the total quantity of bioenergetic substrates (such as adenosine triphosphate (ATP)) leading to stabilization of the cell membrane. This can be potentially protective in states of high energy demand like seizures ${ }^{61}$.

- Antioxidant mechanisms: Ketone bodies have been shown to reduce the amount of coenzyme $\mathrm{Q}$ semiquinone, thereby decreasing free radical production. The KD also induces glutathione peroxidase activity in the rat hippocampus. Glutathione peroxidase is an enzyme found in erythrocytes that prevents lipid peroxidation ${ }^{62,63}$.

In spite of large amounts of ongoing research, the exact underlying cellular or metabolic mechanism of the ketogenic diet remains elusive. More likely the above described hypotheses are either parallel or synergistic in vivo ${ }^{64}$.

\section{How to Initiate the Ketogenic diet}

\section{Patient selection}

Before staring the KD, parental education about the nature of the diet, side effects and benefits is very important. One must ensure that the family is committed to a trial of the diet and have resources available. Meeting a dietician prior to staring the diet is essential. All prescription medications should be changed to carbohydrate free or lowest carbohydrate content forms. Information about over the counter products that have low or no carbohydrates is also provided to families (http://www.charlie foundation.org/resources/low-carb-and-carb-free-products. $\mathrm{html}$ ). Patients and families should understand that once started, this diet has to be followed closely otherwise its beneficial effect is $\operatorname{lost}^{65}$.

There are two specific metabolic conditions in which the KD has unique efficacy, glucose transporter-1 deficiency and and pyruvate dehydrogenase deficiency. In these disorders, the ketogenic diet should be initiated at the time of diagnosis ${ }^{13}$.

\section{Contraindications to the KD}

Absolute contraindications include metabolic disorders including pyruvate carboxylase deficiency, primary carnitine deficiency, defects in fatty acid oxidation including carnitine transporter defects and porphyria.

Relative contraindications include renal stones and hyperlipidemia. Thus metabolic screening must be done before diet initiation ${ }^{13}$. 
Table 4 outlines the recommended initial and follow-up laboratory studies for patients initiating and maintaining a ketogenic diet.

\section{Diet initiation}

The diet may be initialed at home in older children when closely supervised by a dietitian or ketogenic team to guide them. In young children, or those at higher risk of hypoglycemia or dietary intolerance, the diet is often initiated in the hospital under more controlled settings. Children with gastrostomy tubes can be easily initiated on the diet with good compliance ${ }^{66}$. Fasting is not recommended at the time of initiation as was a common practice in the past because it may increase the risk of hypoglycemia and dietary intolerance. The non traditional KD options, including the modified Atkins and low glycemic index diets, can be started at home in most children. If the traditional $\mathrm{KD}$ is being used, it is usually started on a $1: 1$ or $2: 1$ ratio of grams of fat to grams of carbohydrate plus protein. That ratio is advanced slowly to the target ratio. In most children, the target ratio will be $3-4: 1$. Ratio is typically based on the degree of ketosis and seizure control and is different for every child. As discussed previously the degree of ketosis may be less important and in the authors experience, it is recommended to decrease the ratio in patients with significant gastrointestinal intolerance or difficulty with variety of food selections without fear of losing efficacy. Calorie restriction to promote ketosis is not recommended.

The diet requires that patients are maintained on calcium and multivitamin supplementation (carbohydrate free formulation) as the diet is inherently nutritionally incomplete.

\section{Duration of $K D$}

We recommend trying the diet for a minimum period of two to three months, with achievement of at least moderate $(>80$ $160 \mathrm{mg} / \mathrm{dl}$ ) urinary ketosis to determine if the diet will be effective. If the diet is effective, it is usually continued for one to two years, and then gradually weaned. There is considerable variation in practice for the duration of use of $\mathrm{KD}$. In certain syndromes that are likely to relapse after diet weaning, long term use of ketogenic diet is done. Successful use of KD for as long as 12 years in children has been published ${ }^{67}$. In such cases gradual transition of the diet to modified Atkins diet or low glycemic index treatment can be done. The side effects of the long term use of the diet must be carefully weighed against the risk of discontinuation of the diet in patients with intractable epilepsy.

\section{Side Effects (Table 5)}

The traditional KD has more problems with tolerability that the modified versions. A common reason for discontinuation of the diet is felt to be the "too restrictive nature" of the traditional $\operatorname{diet}^{68}$

Acute side effects that can occur immediately upon starting the diet include nausea and vomiting, hypoglycemia, excessive ketosis and acidosis and lethargy ${ }^{41}$. The risk of hypoglycemia is most frequent in the infants and young children who cannot maintain adequate caloric intake and have frequent vomiting. Intolerance due to gastrointestinal side effects is most common reason for the early discontinuation of the diet especially in adults $^{40}$.

Chronic complications include constipation, renal stones due to increased urine calcium/creatinine ratio, cardiomyopathy due to combination of acidosis and selenium deficiency ${ }^{69}$, retarded growth, weight loss, anorexia, progressive bone mineral content $\operatorname{loss}^{70}$, high cholesterol levels, low albumin and carnitine levels (especially when used in combination with valproate $)^{71}$, higher chances of infection, specific vitamin and/or mineral deficiencies (example selenium) if not properly supplemented and rarely fatal pancreatitis in those with abnormal lipid metabolism ${ }^{72-74}$. Though there have been a few cases describing prolonged QT interval on electrocardiogram (EKG) and sudden death in $\mathrm{KD}^{75}$, a systematic study on 27 children (six months-

Table 4: Laboratory studies suggested at initiation and during therapy with the ketogenic diet

\begin{tabular}{l|l}
\hline \multicolumn{2}{l}{ Screening laboratory work before $K \boldsymbol{D}$ initiation } \\
\hline Blood & acylcarnitine, lactate, fasting lipid profile \\
\hline Urine & organic acids, calcium/creatine ratio, urinalysis \\
\hline
\end{tabular}

\section{Laboratory work to be performed at follow up}

Blood (every 3 months)

Urine (every 3 months) complete blood count, electrolytes including calcium, magnesium, phosphorus, albumin, lipase, selenium, alkaline phosphatase, 25-hydroxyvitamin D, fasting lipid profile, carnitine (if on valproate), beta-hydroxybutyrate levels.

Echocardiogram (annually) 
Table 5: Side Effects of the Ketogenic diet

\begin{tabular}{l|l}
\hline Acute & Chronic \\
\hline Nausea and vomiting & Gastrointestinal \\
Hypoglycemia & Constipation \\
Lethargy due to excessive ketosis & Weight loss \\
& Mineral and vitamin deficiency (eg. Selenium, \\
& Vitamin D, calcium) \\
& Pancreatitis \\
& Renal \\
& Stones \\
& Cardiac \\
& Prolonged QT interval \\
& Cardiomyopathy \\
& Growth and development \\
& Short stature \\
& Osteopenia \\
& Laboratory testing \\
& Low albumin \\
& Low carnitine \\
& Abnormal lipid profile (elevated cholesterol) \\
\hline
\end{tabular}

five years) did not find any statistically significant change in the corrected QT interval over one year time period ${ }^{74}$.

\section{Use of KD in other diseases}

\section{Cancer}

A mouse model of malignant glioma has been used to study the effects of KD. Animals fed KD had elevated levels of $\beta$ hydroxybutyrate $(\mathrm{p}=0.0173)$ and an increased median survival of approximately five days relative to animals maintained on a standard diet. In 9 of 11 animals treated with KD plus radiation, the tumor cells diminished below the level of detection $(p<0.0001)$. Thus, based on animal studies, KD significantly enhanced the anti-tumor effect of radiation, suggesting that it may be useful as an adjuvant to the current standard of care for the treatment of human malignant gliomas ${ }^{76}$. A case series of two pediatric patients with anaplastic astrocytoma showed that KD treatment was associated with decreased tumor glucose metabolism as assessed by positron emission tomography (PET). These preliminary results suggest a potential for clinical application which merits further research ${ }^{77}$.

\section{Headache}

The medium chain triglyceride diet has been shown to reduce the velocity of cortical spreading depression in a rat model of migraine ${ }^{78}$. The modified Atkins diet has been studied in patients with chronic daily headache and may have promise ${ }^{79}$.

\section{Autism}

A pilot, prospective follow-up study of a six month trial of the $\mathrm{KD}$ in 30 children, aged 4-10 years, with autistic behavior showed that $18(60 \%)$ had improvement in several parameters on the childhood autism rating scale ${ }^{80}$. These data are very preliminary and a significant limitation is lack of a control group. Further studies are needed before this therapy should be considered for autism.

\section{Head trauma}

It has been shown in animal models of traumatic brain injury that treatment with KD reduces cortical contusion volumes that correlate well with beta hydroxybutyrate levels in serum; suggesting a neuroprotective effect of the diet. Human studies are needed before this therapy is considered in traumatic brain injury patients ${ }^{81}$.

In conclusion, there is emerging evidence that KD may be useful in a broad range of neurological disorders. However, further studies are needed prior to accepting this as standard therapy; underlying mechanism remains to be clearly determined.

\section{Conclusion}

Most individuals who develop epilepsy will respond to pharmacologic treatment, however, approximately 20\%-30\% are pharmacoresistent ${ }^{82}$. For this population, KD can be highly efficacious and should be considered early, as further antiepileptic drug trials have low rates of success. Based on the evidence that is reviewed and authors experience, KD should be offered to both children and adults with intractable epilepsy that is not potentially treatable with surgical options.

\section{REFERENCES}

1. Hippocrates. In: The genuine work of Hippocrates; translated by Francis Adams. Baltimore: Williams and Wilkins; 1939. p. 368-9.

2. G. Guelpa AM. A lutte contre l'epilepsie par la desintoxication et par la reeducation alimentaire. Rev Ther Med Chirurg. 1911;78: 8-13.

3. Conklin HW. Cause and treatment of epilepsy. J Am Osteopathic Assoc. 1922;26:11-14.

4. HR G. Fasting as a method of treating epilepsy. Medical Record. 1921;99:1037-9.

5. Wilder HH. Anthropometric measurements. Science. 1921;53:20.

6. Huttenlocher PR. Ketonemia and seizures: metabolic and anticonvulsant effects of two ketogenic diets in childhood epilepsy. Pediatr Res. 1976;10:536-40. 
7. Huttenlocher PR, Wilbourn AJ, Signore JM. Medium-chain triglycerides as a therapy for intractable childhood epilepsy. Neurology. 1971;21:1097-103.

8. Sinha SR, Kossoff EH. The ketogenic diet. Neurologist. 2005;11: $161-70$.

9. Kinsman SL, Vining EP, Quaskey SA, Mellits D, Freeman JM. Efficacy of the ketogenic diet for intractable seizure disorders: review of 58 cases. Epilepsia. 1992;33:1132-6.

10. Vining EP, Freeman JM, Ballaban-Gil K, et al. A multicenter study of the efficacy of the ketogenic diet. Arch Neurol. 1998;55: 1433-7.

11. Neal EG, Chaffe H, Schwartz RH, et al. The ketogenic diet for the treatment of childhood epilepsy: a randomised controlled trial. Lancet Neurol. 2008;7:500-6.

12. Kossoff EH, McGrogan JR. Worldwide use of the ketogenic diet. Epilepsia. 2005;46:280-9.

13. Kossoff EH, Zupec-Kania BA, Amark PE, et al. Optimal clinical management of children receiving the ketogenic diet: recommendations of the International Ketogenic Diet Study Group. Epilepsia. 2009;50:304-17.

14. Freund G, Weinsier RL. Standardized ketosis in man following medium chain triglyceride ingestion. Metabolism. 1966;15: 980-91

15. Mak SC, Chi CS, Wan CJ. Clinical experience of ketogenic diet on children with refractory epilepsy. Acta Paediatr Taiwan. 1999; 40:97-100.

16. Kossoff EH, McGrogan JR, Bluml RM, Pillas DJ, Rubenstein JE, Vining EP. A modified Atkins diet is effective for the treatment of intractable pediatric epilepsy. Epilepsia. 2006;47:421-4.

17. Chen W, Kossoff EH. Long-term follow-up of children treated with the modified atkins diet. J Child Neurol. 2012; 27:754-8.

18. Pfeifer HH, Thiele EA. Low-glycemic-index treatment: a liberalized ketogenic diet for treatment of intractable epilepsy. Neurology. 2005;65:1810-12.

19. Coppola G, D'Aniello A, Messana T, et al. Low glycemic index diet in children and young adults with refractory epilepsy: first Italian experience. Seizure. 2011;20:526-8.

20. Seo JH, Lee YM, Lee JS, Kang HC, Kim HD. Efficacy and tolerability of the ketogenic diet according to lipid:nonlipid ratios--comparison of 3:1 with 4:1 diet. Epilepsia. 2007;48:801-

21. Hong AM, Turner Z, Hamdy RF, Kossoff EH. Infantile spasms treated with the ketogenic diet: prospective single-center experience in 104 consecutive infants. Epilepsia. 2010;51: 1403-7.

22. Kang HC, Lee YJ, Lee JS, et al. Comparison of short- versus longterm ketogenic diet for intractable infantile spasms. Epilepsia. 2011;52:781-7.

23. Caraballo RH. Nonpharmacologic treatments of Dravet syndrome: focus on the ketogenic diet. Epilepsia. 2011;52 Suppl 2:79-82.

24. Nabbout R, Copioli C, Chipaux M, et al. Ketogenic diet also benefits Dravet syndrome patients receiving stiripentol: a prospective pilot study. Epilepsia. 2011;52:e54-7.

25. Veggiotti P, Burlina A, Coppola G, et al. The ketogenic diet for Dravet syndrome and other epileptic encephalopathies: an Italian consensus. Epilepsia. 2011:52 Suppl 2:83-9.

26. Caraballo RH, Cersosimo RO, Sakr D, et al. Ketogenic diet in patients with myoclonic-astatic epilepsy. Epileptic Disord. 2006; 8:151-5

27. Kilaru S, Bergqvist AG. Current treatment of myoclonic astatic epilepsy: clinical experience at the Children's Hospital of Philadelphia. Epilepsia. 2007;48:1703-7.

28. Oguni H, Tanaka T, Hayashi K, et al. Treatment and long-term prognosis of myoclonic-astatic epilepsy of early childhood. Neuropediatrics. 2002;33:122-32.

29. Freeman JM, Vining EP, Kossoff EH, Pyzik PL, Ye X, Goodman $\mathrm{SN}$. A blinded, crossover study of the efficacy of the ketogenic diet. Epilepsia. 2009;50:322-5.

30. Groomes LB, Pyzik PL, Turner Z, Dorward JL, Goode VH, Kossoff EH. Do patients with absence epilepsy respond to ketogenic diets? J Child Neurol. 2011:26:160-5.
31. Lemmon ME, Terao NN, Ng YT, Reisig W, Rubenstein JE, Kossoff EH. Efficacy of the ketogenic diet in Lennox-Gastaut syndrome: a retrospective review of one institution's experience and summary of the literature. Dev Med Child Neurol. 2012;54: 464-8.

32. Nabbout R, Mazzuca M, Hubert P, et al. Efficacy of ketogenic diet in severe refractory status epilepticus initiating fever induced refractory epileptic encephalopathy in school age children (FIRES). Epilepsia. 2010;51:2033-7.

33. Chapman KE, Kim DY, Rho JM, Ng YT, Kerrigan JF. Ketogenic diet in the treatment of seizures associated with hypothalamic hamartomas. Epilepsy Res. 2011;94:218-21.

34. Caraballo R, Vaccarezza M, Cersosimo R, et al. Long-term followup of the ketogenic diet for refractory epilepsy: multicenter Argentinean experience in 216 pediatric patients. Seizure. 2011; 20:640-5

35. Kossoff EH, Thiele EA, Pfeifer HH, McGrogan JR, Freeman JM. Tuberous sclerosis complex and the ketogenic diet. Epilepsia. 2005;46:1684-6.

36. Nam SH, Lee BL, Lee CG, et al. The role of ketogenic diet in the treatment of refractory status epilepticus. Epilepsia. 2011;52: e181-4.

37. Kang HC, Lee YM, Kim HD, Lee JS, Slama A. Safe and effective use of the ketogenic diet in children with epilepsy and mitochondrial respiratory chain complex defects. Epilepsia 2007;48:82-8

38. Ito Y, Oguni $\mathrm{H}$, Ito $\mathrm{S}$, Oguni M, Osawa M. A modified Atkins diet is promising as a treatment for glucose transporter type 1 deficiency syndrome. Dev Med Child Neurol. 2011;53:658-63.

39. Cusmai R, Martinelli D, Moavero R, et al. Ketogenic diet in early myoclonic encephalopathy due to non ketotic hyperglycinemia. Eur J Paediatr Neurol. 2012;16:509-13.

40. Nangia S, Caraballo RH, Kang HC, Nordli DR, Scheffer IE. Is the ketogenic diet effective in specific epilepsy syndromes? Epilepsy Res. 2012;100:252-7.

41. Mosek A, Natour H, Neufeld MY, Shiff Y, Vaisman N. Ketogenic diet treatment in adults with refractory epilepsy: a prospective pilot study. Seizure. 2009;18:30-3

42. Klein P, Janousek J, Barber A, Weissberger R. Ketogenic diet treatment in adults with refractory epilepsy. Epilepsy Behav. 2010;19:575-9.

43. Kossoff EH, Rowley H, Sinha SR, Vining EP. A prospective study of the modified Atkins diet for intractable epilepsy in adults. Epilepsia. 2008;49:316-19.

44. Henderson CB, Filloux FM, Alder SC, Lyon JL, Caplin DA. Efficacy of the ketogenic diet as a treatment option for epilepsy: meta-analysis. J Child Neurol. 2006;21:193-8.

45. Klinkenberg S, Aalbers MW, Vles JS, et al. Vagus nerve stimulation in children with intractable epilepsy: a randomized controlled trial. Dev Med Child Neurol. 2012;54:855-61.

46. Kwan P, Brodie MJ. Early identification of refractory epilepsy. N Engl J Med. 2000; 342:314-19.

47. Rho JM, Anderson GD, Donevan SD, White HS. Acetoacetate, acetone, and dibenzylamine (a contaminant in 1-(+)-betahydroxybutyrate) exhibit direct anticonvulsant actions in vivo. Epilepsia. 2002;43:358-61.

48. Dutton SB, Sawyer NT, Kalume F, et al. Protective effect of the ketogenic diet in Scn1 a mutant mice. Epilepsia. 2011;52:2050-6.

49. Bough KJ, Yao SG, Eagles DA. Higher ketogenic diet ratios confer protection from seizures without neurotoxicity. Epilepsy Res. 2000;38:15-25.

50. Stafstrom CE, Rho JM. The ketogenic diet as a treatment paradigm for diverse neurological disorders. Front Pharmacol. 2012;3:59.

51. Fraser DD, Whiting S, Andrew RD, Macdonald EA, Musa-Veloso $\mathrm{K}$, Cunnane SC. Elevated polyunsaturated fatty acids in blood serum obtained from children on the ketogenic diet. Neurology. 2003;60:1026-9.

52. Auvin S. Fatty acid oxidation and epilepsy. Epilepsy Res. 2012; 100:224-8.

53. Bromfield E, Dworetzky B, Hurwitz S, et al. A randomized trial of polyunsaturated fatty acids for refractory epilepsy. Epilepsy Behav. 2008;12:187-90. 
54. DeGiorgio CM, Miller P, Meymandi S, Gornbein JA. n-3 fatty acids (fish oil) for epilepsy, cardiac risk factors, and risk of SUDEP: clues from a pilot, double-blind, exploratory study. Epilepsy Behav. 2008;13:681-4.

55. Jeong EA, Jeon BT, Shin HJ, et al. Ketogenic diet-induced peroxisome proliferator-activated receptor-gamma activation decreases neuroinflammation in the mouse hippocampus after kainic acid-induced seizures. Exp Neurol. 2011;232:195-202.

56. Noh HS, Hah YS, Nilufar R, et al. Acetoacetate protects neuronal cells from oxidative glutamate toxicity. J Neurosci Res. 2006;83: 702-9.

57. Dahlin M, Mansson JE, Amark P. CSF levels of dopamine and serotonin, but not norepinephrine, metabolites are influenced by the ketogenic diet in children with epilepsy. Epilepsy Res. 2012; 99:132-8.

58. Chmiel-Perzynska I, Kloc R, Perzynski A, Rudzki S, Urbańska EM. Novel aspect of ketone action: beta-hydroxybutyrate increases brain synthesis of kynurenic acid in vitro. Neurotox Res. 2011; 20:40-50.

59. Daikhin Y, Yudkoff M. Ketone bodies and brain glutamate and GABA metabolism. Dev Neurosci. 1998;20:358-64.

60. Kumada T, Nishii R, Higashi T, et al. Ketogenic diet may control seizures by increasing the binding potential of the benzodiazepine receptor: a speculation from the [11C] flumazenil-PET study. No To Hattatsu. 2012;44:50-4.

61. DeVivo DC, Leckie MP, Ferrendelli JS, McDougal DB Jr. Chronic ketosis and cerebral metabolism. Ann Neurol. 1978;3:331-7.

62. Veech RL. The therapeutic implications of ketone bodies: the effects of ketone bodies in pathological conditions: ketosis, ketogenic diet, redox states, insulin resistance, and mitochondrial metabolism. Prostaglandins Leukot Essent Fatty Acids. 2004;70:309-19.

63. Ziegler DR, Ribeiro LC, Hagenn M, et al. Ketogenic diet increases glutathione peroxidase activity in rat hippocampus. Neurochem Res. 2003;28:1793-7.

64. Gasior M, Rogawski MA, Hartman AL. Neuroprotective and disease-modifying effects of the ketogenic diet. Behav Pharmacol. 2006;17:431-9.

65. Livingston S. The ketogenic diet in the treatment of epilepsy in children. Postgrad Med. 1951;10:333-6.

66. Hosain SA, La Vega-Talbott M, Solomon GE. Ketogenic diet in pediatric epilepsy patients with gastrostomy feeding. Pediatr Neurol. 2005;32:81-3.

67. Groesbeck DK, Bluml RM, Kossoff EH. Long-term use of the ketogenic diet in the treatment of epilepsy. Dev Med Child Neurol. 2006;48:978-81.

68. Freeman JM, Vining EP, Pillas DJ, Pyzik PL, Casey JC, Kelly LM. The efficacy of the ketogenic diet-1998: a prospective evaluation of intervention in 150 children. Pediatrics. 1998;102:1358-63.
69. Sirikonda NS, Patten WD, Phillips JR, Mullett CJ. Ketogenic diet: rapid onset of selenium deficiency-induced cardiac decompensation. Pediatr Cardiol. 2012;33:834-8.

70. Bergqvist AG, Schall JI, Stallings VA, Zemel BS. Progressive bone mineral content loss in children with intractable epilepsy treated with the ketogenic diet. Am J Clin Nutr. 2008;88:1678-84.

71. Coppola G, Epifanio G, Auricchio G, Federico RR, Resicato G, Pascotto A. Plasma free carnitine in epilepsy children, adolescents and young adults treated with old and new antiepileptic drugs with or without ketogenic diet. Brain Dev. 2006;28:358-65.

72. Buse GJ, Riley KD, Dress CM, Neumaster TD. Patient with gemfibrozil-controlled hypertriglyceridemia that developed acute pancreatitis after starting ketogenic diet. Curr Surg. 2004; 61:224-6.

73. Panico LR, Demartini MG, Rios VG, Carniello MA. The ketogenic diet in infantile refractory epilepsy: electroclinical response, complications and secondary effects. Revista de Neurologia. 2000;31:212-20.

74. Sharma S, Gulati S. The ketogenic diet and the QT interval. J Clin Neurosci. 2012;19:181-2.

75. Bank IM, Shemie SD, Rosenblatt B, Bernard C, Mackie AS. Sudden cardiac death in association with the ketogenic diet. Pediatr Neurol. 2008;39:429-31.

76. Abdelwahab MG, Fenton KE, Preul MC, et al. The ketogenic diet is an effective adjuvant to radiation therapy for the treatment of malignant glioma. PLoS One. 2012;7:e36197.

77. Nebeling LC, Miraldi F, Shurin SB, Lerner E. Effects of a ketogenic diet on tumor metabolism and nutritional status in pediatric oncology patients: two case reports. J Am Coll Nutr. 1995;14: 202-8.

78. de Almeida Rabello Oliveira M, da Rocha Ataide T, de Oliveira SL, et al. Effects of short-term and long-term treatment with medium- and long-chain triglycerides ketogenic diet on cortical spreading depression in young rats. Neurosci Lett. 2008;434: 66-70.

79. Kossoff EH, Huffman J, Turner Z, Gladstein J. Use of the modified Atkins diet for adolescents with chronic daily headache. Cephalalgia. 2010;30:1014-16.

80. Evangeliou A, Vlachonikolis I, Mihailidou H, et al. Application of a ketogenic diet in children with autistic behavior: pilot study. J Child Neurol. 2003;18:113-18.

81. Prins ML. Cerebral metabolic adaptation and ketone metabolism after brain injury. J Cereb Blood Flow Metab. 2008;28:1-16.

82. Sillanpaa M, Schmidt D. Natural history of treated childhood-onset epilepsy: prospective, long-term population-based study. Brain. 2006;129:617-24. 